\title{
Electron transfer reaction and demetalation of phthalocyanines
}

\author{
Jean Kossanyi and Driss Chahraoui \\ Laboratoire des Matériaux Moléculaires, C.N.R.S., 2-8, rue Henri Dunant, 94320-Thiais (France)
}

\begin{abstract}
An electron-transfer reaction takes place in the ground state between phthalocyanines (as electron-donors) and pyrylium cations (as electron-acceptors) in polar solvents, reaction which leads to the phthalocyanine radical-cations as evidenced by its absorption spectra identical to the one of the species formed by electrochemical oxidation.

The fluorescence emission of the phthalocyanines is quenched by electron-acceptors (principally quinones). The free energy change $\Delta G_{\mathrm{CT}}$ of the electron-transfer reaction has been evaluated for each electron acceptor with a solvation energy of $0.14 \mathrm{eV}$ in the case of dimethylformamide and $1.2 \mathrm{eV}$ in that of dichloromethane. The rate constant of the quenching of the phthalocyanines singlet excited state by a series of electronacceptors is found to be of the order of $1.2-1.5 \times 10^{10} \mathrm{~L} \cdot \mathrm{mol}^{-1} \mathrm{~s}^{-1}$.

Metalated phthalocyanines are demetalated in the dark by hydroxy-anthraquinones with a rate constant of the order of $10^{-2} \mathrm{~L} \cdot \mathrm{mol}^{-1} \mathrm{~s}^{-1}$ at $292 \mathrm{~K}$ and which increases (up to $7 \times 10^{-2} \mathrm{~L} \cdot \mathrm{mol}^{-1} \mathrm{~s}^{-1}$ at $349 \mathrm{~K}$ ) with temperature. The activation energy of the demetalation reaction has been determined to be ca $30 \mathrm{~kJ} \cdot \mathrm{mol}^{-1}$ for 1,4-dihydroxyanthraquinone and $35 \mathrm{~kJ} \cdot \mathrm{mol}^{-1}$ for 1,2,4-trihydroxyanthraquinone.
\end{abstract}

\section{INTRODUCTION}

Metallophthalocyanines present a fluorescence emission which is characterized by a narrow band at long wavelengths between 670 and $710 \mathrm{~nm}$. Their structure is similar to that of porphyrines but their strong absorption ( $\varepsilon=120,000$ to $180,000 \mathrm{M}^{-1} \mathrm{~cm}^{-1}$ ) at around $680 \mathrm{~nm}$ is about three orders of magnitude higher than that of the porphyrins in the visible region. This has lead them to be proposed as model compounds[1, 2] and as substitutes of porphyrins in the phototherapy of tumors.

Metal-free and metalated phthalocyanines (except those with a transition metal central atom [3, 4]) present an important fluorescence emission $[5,6,7]$. This fluorescence can be quenched by various electronacceptors and the decrease of the fluorescence quantum yield with the increase of the concentration of the quencher in the solution follows the usual SternVolmer relationship [5, 8]. No interaction of the ground state phthalocyanines with strong electron-acceptors has been claimed, up to now. It is part of this article to describe such ground state reaction which leads to the formation of the phthalocyanine radical-cation.

The reaction of demetalation of porphyrines is an important process which must be carried out in the petrochemical industry. Effectively, petroleum crudes contain small amounts of nickel and vanadium porphyrines $[9,10]$ which are converted [11] into $\mathrm{V}_{2} \mathrm{~S}_{3}$ during the hydrodesulfurization reaction of the crude oils, thus poisoning the $\mathrm{Co}-\mathrm{Mo} / \mathrm{Al}_{2} \mathrm{O}_{3}$ catalyst [12] used for the reaction. Phthalocyanines which have a structure similar to that of porphyrines have been used as model compounds in the study of the demetalation reaction. Hot concentrated sulfuric acid has been shown to demetalate both metal phthalocyanines and metal porphyrines $[13,14,15]$. Dilithium phthalocya- nine is demetalated easily in weakly coordinating solvents such as dimethylacetamide or dimethylsulfoxide, in the presence of trifluoroacetic acid [16]. In the course of our investigations on the electron donor-acceptor interaction of phthalocyanines, we observed that few metalated ones underwent a demetalation reaction. It is the purpose of this article to describe such demetalation process.

\section{ELECTRON TRANSFER IN THE GROUND STATE}

Electron transfer between two ground state molecules forms a complex which can be characterized by the appearance of a new absorption band at wavelengths longer than the absorption of the two reactants [17]. Pyrylium ions are known for their excellent electron attracting properties $[18,19]$. When pyrylium ions are added to a dimethylformamide (DMF) solution of metal phthalocyanines, an electron-exchange reaction occurs between the two ground state molecules which forms the radical-cation of the phthalocyanine and transforms the pyrylium cation into the pyrylium radical. The reaction rate constant being small, high concentrations $\left(>10^{-3} \mathrm{~mol} \cdot \mathrm{L}^{-1}\right)$ of the pyrylium ion are needed to carry the electron exchange reaction. Figure 1 shows the change of the absorption spectra of chloroaluminium phthalocyanine $\left(510^{-6} \mathrm{~mol} \cdot \mathrm{L}^{-1}\right)$ in DMF solution before and after the addition of $5 \times 10^{-3} \mathrm{~mol} \cdot \mathrm{L}^{-1}$ of 2,6-diphenyl-4-benzylpyrylium perchlorate.

The spectra obtained by this method are identical to those of the phthalocyanine radical-cations formed either by electrochemical oxidation or by photochemical reaction [20] of the metal phthalocyanines in the presence of carbon tetrabromide according to relation (1):

$$
\mathrm{MgPc}+\mathrm{CBr}_{4} \stackrel{h v}{\rightarrow} \mathrm{MgPc}^{+}+\mathrm{CBr}_{3}^{\cdot}+\mathrm{Br}^{-}
$$




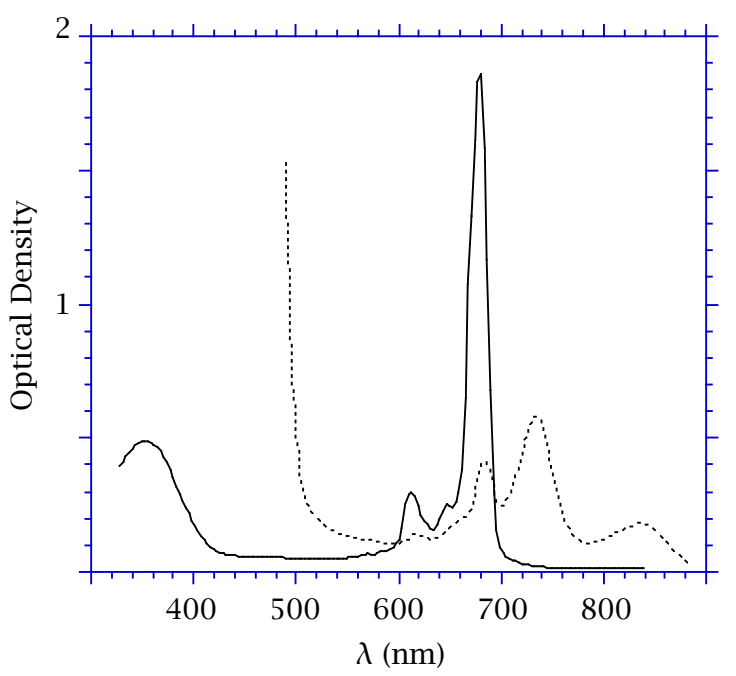

Figure 1. Absorption spectra of chloroaluminium phthalocyanine in DMF solution: (-) before and (- - ) after addition of 2,6-diphenyl-4-benzylpyrylium perchlorate $(5 \times$ $10^{-3} \mathrm{~mol} \cdot \mathrm{L}^{-1}$ ).

\section{ELECTRON TRANSFER IN THE EXCITED STATE}

Irradiation of phthalocyanines in their long wavelength absorption band (ca. $640 \mathrm{~nm}$ ) forms the singlet excited state which deactivates mainly by fluorescence emission and by intersystem crossing to the triplet state (Table 1). Several articles report [21, 22, 23, 24, $25,26]$ the electron donating behaviour of the singlet excited state of phthalocyanines with respect to methylviologene. Metal-free and most of the metalated phthalocyanines show an important fluorescence emission [5, 6, 7]. Addition of a series of electron acceptors (principally quinones) to the phthalocyanines solution quenches their fluorescence $[5,8]$ and the quenching follows the usual Stern-Volmer relationship from which the quenching rate constant can be deduced.

The anthraquinones have been shown already to behave as good electron-acceptors in donor-acceptor (DA) electron transfer reactions in the excited state [29]. No ground state complex could be detected on the absorption spectra of the reactive mixture because of the intense absorption of the phthalocyanines at long wavelengths. However, for the same donor, the position of the charge transfer complex absorption varies with the reduction potential of the acceptor. In the case described here, $\mathrm{E}_{A}^{\mathrm{red}}$ varies from -1.63 to $-0.08 \mathrm{~V} / \mathrm{SCE}$ (Table 2). With such a large potential range, if a ground state complex would have been formed, its absorption with at least one of the donor molecules should have been observed at longer wavelengths. No exciplex emission could be observed for all the D-A couples, as expected from the high polarity ( $\varepsilon=34$ for DMF) of the solvent used in this study.

The fluorescence quenching rate constant does not vary when exciting metal free phthalocyanine $\left(\mathrm{H}_{2} \mathrm{Pc}\right)$ or magnesium phthalocyanine (MgPc) at different wavelengths $\left(604,630\right.$, and $660 \mathrm{~nm}$ for $\mathrm{H}_{2} \mathrm{Pc}, 604,630,656$ and $690 \mathrm{~nm}$ for $\mathrm{MgPc}$ ) in the presence of the same electron-acceptor [30]. The contrary has been observed when the phthalocyanines act as electron-acceptors in the presence of a strong electron-donating species [31].

The rate constant of the electron-exchange reaction between the phthalocyanines and the electronacceptors increases as the reduction potential $\mathrm{E}_{A}^{\mathrm{red}}$ of the acceptor decreases. Below a certain value of $E_{A}^{\text {red }}$ the rate constant reaches a plateau which corresponds to the diffusion rate constant. Such behaviour is in all points identical to the one described by Rehm and Weller in other cases [32, 33, 34]. The free energy change $\Delta G_{\mathrm{CT}}$ of the electron transfer reaction which occurs between the phthalocyanines (of oxidation potential $E_{D}^{o x}$ and the electron acceptor is given by:

$$
\Delta G_{\mathrm{CT}}=E_{D}^{o x}-E_{A}^{\mathrm{red}}-\Delta E_{s}-\Delta H_{\mathrm{sol}}+0.32
$$

where $\Delta E_{s}$ is the energy of the lowest singlet excited state of the phthalocyanine, $\Delta H_{\text {sol }}$ is the solvatation energy, i.e., the stabilization energy by the medium of polarity $\varepsilon$ and of refractive index $\mathrm{n}$ (1.42 for DMF):

$$
\Delta H_{\mathrm{sol}}=\frac{e^{2} d^{2}}{4 \pi \varepsilon_{0} r^{3}}\left[\frac{2(\varepsilon-1)}{(2 \varepsilon-1)}-\frac{n^{2}-1}{2 n^{2}-1}\right]
$$

$\varepsilon_{0}$ is the vacuum permittivity $\left(8.84 \times 10^{-12} \mathrm{Farad} \cdot \mathrm{m}^{-1}\right)$, $e$ is the charge of the electron $\left(1.6 \times 10^{-19}\right.$ Coulomb), $d$ is the distance (in meter) between the electric dipoles created in the charge transfer complex $(6 \times$ $10^{-10} \mathrm{~m}$, in the case of the phthalocyanines with the anthraquinones),

Table 1. Spectroscopic data of the phthalocyanines. (a) by comparison with Crystal Violet $\left(\Phi_{f}=0.56\right)$ in methanol; ref. [27] (b) in 1-chloronaphthalene (ref. [28])

\begin{tabular}{c|ccccccc}
\hline Phthalocyanine & $\mathrm{H}_{2} \mathrm{Pc}$ & $\mathrm{Li}_{2} \mathrm{Pc}$ & $\mathrm{MgPc}$ & $\mathrm{AlClPc}$ & $\mathrm{TiPc}$ & $\mathrm{CuPc}$ & $\mathrm{ZnPc}$ \\
\hline Solvent & $\mathrm{CHCl}_{3}$ & $\mathrm{DMF}$ & $\mathrm{DMF}$ & $\mathrm{DMF}$ & $\mathrm{CHCl}_{3}$ & $\mathrm{DMF}$ & $\mathrm{DMF}$ \\
\hline$\Phi_{f}^{(\mathrm{a})}$ & 0.55 & 0.54 & & 0.68 & 0.42 & 0.09 & 0.31 \\
\hline$\Phi_{\mathrm{isc}}$ & $0.14^{(\mathrm{b})}$ & 0.41 & 0.28 & 0.22 & 0.56 & $0.70^{(\mathrm{b})}$ & 0.58 \\
\hline$\tau_{s}(\mathrm{~ns})$ & 6.5 & 7.2 & 10.2 & 9.7 & 3.9 & & 4.1 \\
\hline$\tau_{T}(\mu \mathrm{s})$ & $130^{(\mathrm{b})}$ & 3.7 & 445 & & 26.7 & $0.04^{(\mathrm{b})}$ & 35.6 \\
\hline
\end{tabular}


Table 2. Redox potential of the electron-acceptors (a) in DMSO; (b) in DMF. Logarithm of the phthalocyanine fluorescence inhibition rate constant $k$ and value of the free energy change (in eV) of the charge transfer complex formtion.

\begin{tabular}{|c|c|c|c|c|c|c|c|c|c|c|c|c|c|c|c|}
\hline ELECTROA & CCEPTOR & 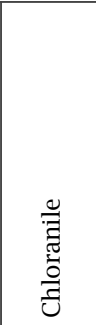 & 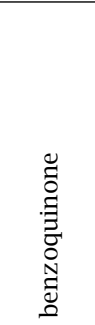 & 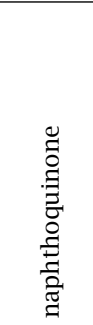 & 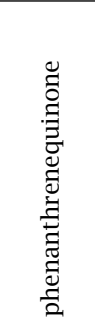 & 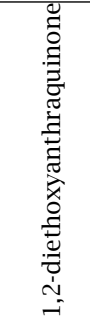 & 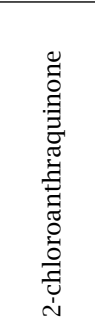 & 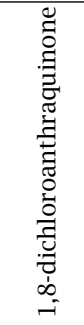 & 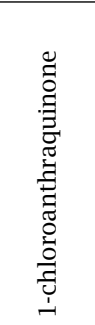 & 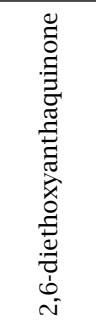 & 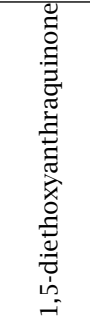 & 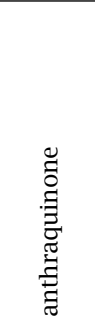 & 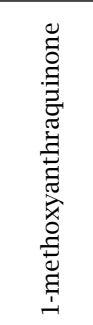 & 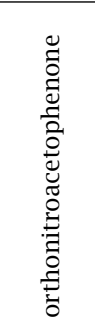 & 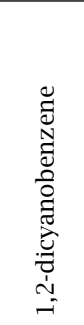 \\
\hline \multirow[t]{2}{*}{$-E_{A}^{\mathrm{red}}$} & $(\mathrm{V})$ & $0.08^{(\mathrm{a})}$ & $0.48^{(\mathrm{b})}$ & $0.60^{(\mathrm{b})}$ & $0.66^{(\mathrm{b})}$ & $0.74^{(\mathrm{b})}$ & $0.78^{(b)}$ & $0.79^{(b)}$ & $0.83^{(\mathrm{b})}$ & $0.85^{(\mathrm{b})}$ & $0.86^{(\mathrm{b})}$ & $0.88^{(\mathrm{b})}$ & $0.94^{(\mathrm{b})}$ & $1.07^{(\mathrm{b})}$ & $1.63^{(\mathrm{a})}$ \\
\hline & $\log (k)$ & 10.21 & 10.19 & 10.20 & 10.20 & 10.14 & 10.11 & 10.10 & 10.04 & & 9.95 & 9.89 & 9.72 & 8.97 & \\
\hline \multirow{2}{*}{$\mathrm{H}_{2} \mathrm{Pc}\left(\mathrm{CH}_{2} \mathrm{Cl}_{2}\right)$} & $\Delta G_{\mathrm{CT}}(\mathrm{eV})$ & -0.78 & -0.38 & -0.26 & -0.20 & -0.12 & -0.08 & -0.07 & -0.03 & & 0.00 & +0.03 & +0.08 & +0.21 & \\
\hline & $\log (k)$ & & 10.08 & 9.98 & 10.13 & & 10.12 & 10.10 & 9.90 & & & 9.75 & 9.72 & 8.65 & 8.16 \\
\hline \multirow[t]{2}{*}{$\operatorname{MgPc}(\mathrm{DMF})$} & $\Delta G_{\mathrm{CT}}(\mathrm{eV})$ & & -0.55 & -0.43 & -0.37 & & -0.25 & -0.24 & -0.20 & & & -0.14 & -0.09 & +0.04 & +0.60 \\
\hline & $\log (k)$ & 10.01 & 10.04 & 10.03 & 10.06 & 10.00 & 9.90 & 9.91 & 9.71 & & 9.53 & 9.54 & 9.13 & 8.23 & \\
\hline \multirow[t]{2}{*}{ AlClPc (DMF) } & $\Delta G_{\mathrm{CT}}(\mathrm{eV})$ & -0.62 & -0.22 & -0.10 & -0.04 & +0.04 & +0.08 & +0.09 & +0.13 & & +0.16 & +0.19 & +0.24 & +0.37 & \\
\hline & $\log (k)$ & 10.20 & 10.09 & 10.23 & 10.19 & 10.17 & 10.13 & 10.16 & 10.09 & 10.02 & 9.88 & 9.86 & 9.70 & 9.25 & \\
\hline \multirow[t]{2}{*}{$\operatorname{TiPc}\left(\mathrm{CH}_{2} \mathrm{Cl}_{2}\right)$} & $\Delta G_{\mathrm{CT}}(\mathrm{eV})$ & -0.69 & -0.29 & -0.17 & -0.11 & -0.03 & +0.01 & +0.02 & +0.06 & +0.08 & +0.09 & +0.12 & +0.17 & +0.30 & \\
\hline & $\log (k)$ & 10.21 & 10.00 & 10.00 & 10.00 & 9.92 & 9.94 & 10.00 & 9.94 & & 9.77 & 9.76 & 9.72 & 9.38 & 8.24 \\
\hline ZnPc (DMF) & $\Delta G_{\mathrm{CT}}(\mathrm{eV})$ & -0.88 & -0.48 & -0.36 & -0.30 & -0.22 & -0.18 & -0.17 & -0.13 & & -0.10 & -0.07 & -0.02 & +0.11 & +0.67 \\
\hline
\end{tabular}

$r$ is the radius of the spherical cavity (in meter) occupied by the charge transfer complex (the value $14 \times$ $10^{-10} \mathrm{~m}$ is deduced from the molecular radii). The calculations give $H_{\mathrm{sol}}=0.14 \mathrm{eV}$ for $\mathrm{DMF}$ and 0.12 for dichloromethane, leading to the $\Delta G_{\mathrm{CT}}$ values deduced from relation (2) and given in Table 2 for the different electron acceptors.

The experimental rate constant of the electron tranfer reaction follows an Arrhenius-type relation:

$$
k=\alpha e^{-\Delta G_{\mathrm{CT}} / R T}
$$

$\alpha$ being a constant which includes the frequency factor and various rate constants. The plot of $\log (k)$ versus $\Delta G_{\mathrm{CT}}$ for the various electron acceptors gives the curves shown in Figure 2 with a plateau at $k=1.5 \times$ $10^{10} \mathrm{~L} \cdot \mathrm{mol}^{-1} \cdot \mathrm{s}^{-1}$ in case of $\mathrm{CH}_{2} \mathrm{Cl}_{2}$ and at $k=1.2 \times$ $10^{10} \mathrm{~L} \cdot \mathrm{mol}^{-1} \cdot \mathrm{s}^{-1}$ in case of DMF for the low values of the reduction potential of the acceptor.

In DMF, the slopes of the curves in the high $\Delta G_{\mathrm{CT}}$ range are quite different for $\mathrm{MgPc}$ and $\mathrm{ZnPc}$ as compared to those of the three other phthalocyanines. This has been attributed [5] to the absence of complexation of their central metal atom enabling the promotion of an interaction between the lowest $\pi, \pi^{*}$ excited state localized on the ligand and the metal to ligand charge transfer state. This interaction would increase the electron transfer reaction and, as a consequence, the rate constant of the quenching of the phthalocyanine fluorescence by the electron attractor.

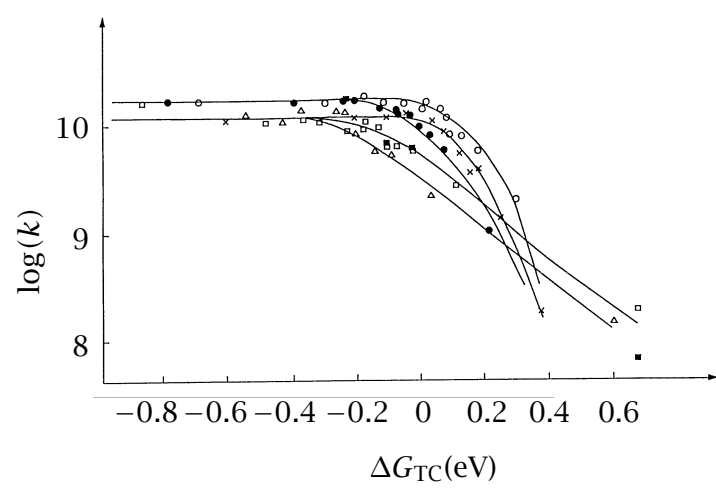

Figure 2. Variation of the logarithm of the fluorescence quenching rate constant $\log \left(k_{v}\right)$ of $\mathrm{H}_{2} \mathrm{Pc}(\bullet \bullet \bullet), \mathrm{MgPc}$ $,(\Delta \Delta \Delta \Delta)$ ClAlPc $(\times \times \times \times)$, TiPc ( $\circ \circ \circ \circ \circ)$ and ZnPc (o o o a) by a series of electron accepting molecules versus the free energy change $\Delta G_{\mathrm{CT}}$ of the electron exchange reaction.

\section{DEMETALATION}

As already pointed out, the reaction of demetalation of porphyrines is an important process in the petrochemical industry since petroleum crudes contain small amounts of nickel and vanadium porphyrines $[9,10]$ which are converted [11] into $\mathrm{V}_{2} \mathrm{~S}_{3}$ during the hydrodesulfurization reaction of the crude oils, a strong poison of the $\mathrm{Co}-\mathrm{Mo} / \mathrm{Al}_{2} \mathrm{O}_{3}$ catalyst [12] used for the reaction. Because of their structure similar to that of 
porphyrines, phthalocyanines have been used as model compounds in the study of the demetalation reaction. Usually, hot concentrated sulfuric acid is used to demetalate both metal phthalocyanines and metal porphyrines [13, 14, 15] except for dilithium phthalocyanine which is demetalated easily in dimethylacetamide in the presence of trifluoroacetic acid or even of only pure water [16].

During the study of the light-induced electron transfer reaction between phthalocyanines and a variety of electron-acceptors [5], MgPc was found to undergo a demetalation process when treated with 1,4dihydroxyanthraquinone $\left(1,4-\mathrm{AQ}(\mathrm{OH})_{2}\right)$ in dimethylformamide solution. As the demetalation of porphyrines can be induced by solvated electrons [35], and as it has been reported $[36,37]$ to occur during electrochemical reduction, the process observed under irradiation in the presence of $1,4-\mathrm{AQ}(\mathrm{OH})_{2}$ could have originated from an electron transfer reaction at the level of the phthalocyanine singlet excited state. However, a blank experiment carried out in the dark at the same time as the experiment under irradiation showed that the demetalation reaction did not need light to occur.

The blank experiment with $1,4-\mathrm{AQ}(\mathrm{OH})_{2}$ could be followed by the decrease with time of the intense absorption band of MgPc at $668 \mathrm{~nm}$ and by the concomitent growth of two new bands absorbing at 654 and $688 \mathrm{~nm}$ (Figure 3). These two bands have been attributed to the metal-free phthalocyanine formed by the following general reaction scheme:

$$
\mathrm{MgPc}+1,4-\mathrm{AQ}(\mathrm{OH})_{2} \rightarrow \mathrm{H}_{2} \mathrm{Pc}+1,4-\mathrm{AQ}\left(\mathrm{O}_{2} \mathrm{Mg}\right)
$$

The structure of this metal-free phthalocyanine could be characterized by mass spectrometry as well as by microanalysis. The rate of the demetalation reaction is expressed by :

$$
v=-\frac{d[\mathrm{MgPc}]}{d t}=-k_{v}[\mathrm{MgPc}]\left[\mathrm{AQ}(\mathrm{OH})_{2}\right],
$$

where $k_{v}$ is the demetalation reaction rate constant while $[\mathrm{MgPc}]$ and $\left[\mathrm{AQ}(\mathrm{OH})_{2}\right]$ are the concentrations of magnesium phthalocyanine and 1,4-dihydroxyanthraquinone, respectively. For a $2 \times 10^{-3} \mathrm{~mol} \cdot \mathrm{L}^{-1}$ concentration of $\left[\mathrm{AQ}(\mathrm{OH})_{2}\right], 400$ times larger than that of [MgPc], the only variable with time becomes [MgPc]; consequently, relation (6) can now be changed into (7):

$$
[\mathrm{MgPc}]=[\mathrm{MgPc}]_{o} e^{-k_{\mathrm{app}} \tau} .
$$

In this expression, $k_{\mathrm{app}}=400 k_{v}$ is the apparent reaction rate constant, $[\mathrm{MgPc}]_{o}$ being the concentration of MgPc at time $\tau=0$. The evolution with time of the absorption spectrum shows (Figure 3 ) four isosbestic points at $\lambda=600,616,658$, and $680 \mathrm{~nm}$ which agree with a first order reaction in which MgPc is transformed into $\mathrm{H}_{2} \mathrm{Pc}$ (vide infra). During this transformation, the global concentration is found to remain constant (based on the known molecular extinction coefficients $\epsilon$ of the two species), thus corroborating that the rate of formation of $\mathrm{H}_{2}$ Pc is identical to the rate of disappearance of MgPc.

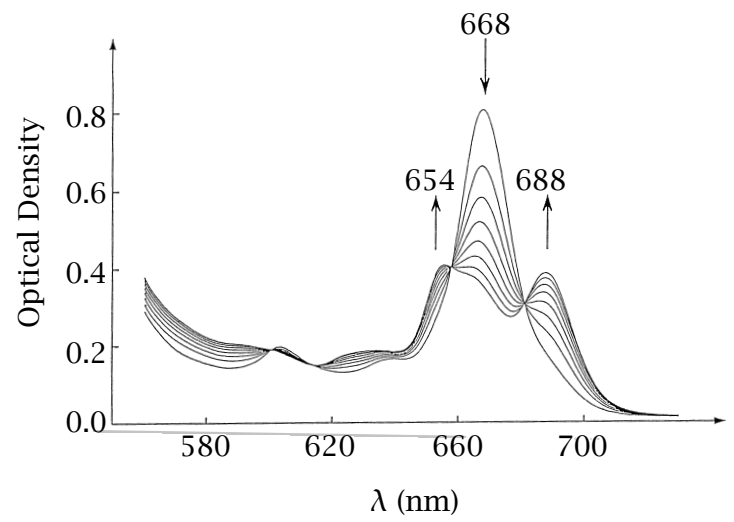

Figure 3. Evolution of the absorption spectra of MgPc $\left(5 \times 10^{-6} \mathrm{~mol} \cdot \mathrm{L}^{-1}\right)$ with time in the presence of 1,4 dihydroxyanthraquinone $\left(2 \times 10^{-3} \mathrm{~mol} \cdot \mathrm{L}^{-1}\right)$.

Plotting $\ln \left([\mathrm{MgPc}]^{\circ} /[\mathrm{MgPc}]\right)$ versus time gives straight lines (Figure 4) the slope of which corresponds to the apparent rate constant $k_{\text {app }}$ from which the actual reaction rate constant can be deduced.

When the temperature of the solution is increased, the rate of the demetalation reaction increases (Table 3) and follows an Arrhenius type expression:

$$
k_{v}=A e^{-\Delta E_{a} / R T},
$$

where $A$ is the frequency factor, $\Delta E_{a}$ the reaction activation energy (in $\mathrm{kJ} \cdot \mathrm{mol}^{-1}$ ), and $\mathrm{R}$ the gas constant $\left(8.3 \mathrm{~J} \cdot \mathrm{mol}^{-1} \cdot \mathrm{K}^{-1}\right)$.

A similar temperature-dependent demetalation reaction is observed when 1,2,4-trihydroxyanthraquinone (represented by $\mathrm{AQ}(\mathrm{OH})_{3}$ ) is substituted to 1,4dihydroxyanthraquinone (Table 3 ). In both cases it was demonstrated by comparison with authentical samples, that the polyhydroxyanthraquinone is transformed into the corresponding magnesium derivative [30].

The plot of $\ln k_{v}$ versus the reciprocal of the absolute temperature, gives straight lines (Figure 5) from which the activation energy and the frequency factor of the reaction can be deduced. The obtained values for the activation energy $\left(c a .30 \mathrm{~kJ} \cdot \mathrm{mol}^{-1}\right)$ indicate that the reaction can occur easily.

Berezina et al [13] have shown that the entropy of the demetalation reaction $\Delta S^{ \pm}$follows the relation:

$$
\Delta S^{ \pm}=8.314 \ln \left(k_{v}\right)_{T}+\frac{\Delta E_{a}}{T}-253.22
$$

The entropy value deduced from this expression for the demetalation reaction of MgPc by the hydroxylated anthraquinones $\mathrm{AQ}(\mathrm{OH})_{2}$ and $\mathrm{AQ}(\mathrm{OH})_{3}$ is of the order of $0.18 \mathrm{~kJ} \cdot \mathrm{mol}^{-1} \cdot \mathrm{K}^{-1}$ (Table 3 ).

This demetation reaction by $\mathrm{AQ}(\mathrm{OH})_{2}$ and $\mathrm{AQ}(\mathrm{OH})_{3}$ occurs also with dilithium phthalocyanine and with sodium phthalocyanine but not with the other metal (chloroaluminium, titanium, manganese, iron, cobalt, nickel, copper, zinc) phthalocyanines. Such a difference can be related to the nature of the bonding between 
Table 3. Kinetic and thermodynamic data of the demetalation reaction of magnesium phthalocyanine by two hydroxylated anthraquinones.

\begin{tabular}{|c|c|c|c|c|c|c|c|c|}
\hline Quinone & \multicolumn{4}{|c|}{ 1,4-dihydroxyanthraquinone } & \multicolumn{4}{|c|}{ 1,2,4-trihydroxyanthraquinone } \\
\hline $\mathrm{T}(\mathrm{K})$ & 292 & 313 & 337 & 349 & 295 & 316 & 334 & 347 \\
\hline$k_{v}\left(\mathrm{~L} \cdot \mathrm{mol}^{-1} \cdot \mathrm{s}^{-1}\right)$ & 0.0096 & 0.0251 & 0.050 & 0.0737 & 0.0291 & 0.775 & 0.1517 & 0.2405 \\
\hline$E_{a}\left(\mathrm{~kJ} \cdot \mathrm{mol}^{-1}\right)$ & \multicolumn{4}{|c|}{30.4} & \multicolumn{4}{|c|}{34.7} \\
\hline A & \multicolumn{4}{|c|}{$2.8 \times 10^{3}$} & \multicolumn{4}{|c|}{$4.2 \times 10^{4}$} \\
\hline$\Delta S^{ \pm}\left(\mathrm{kJ} \cdot \mathrm{mol}^{-1} \cdot \mathrm{K}^{-1}\right)$ & \multicolumn{4}{|c|}{0.17} & \multicolumn{4}{|c|}{0.19} \\
\hline
\end{tabular}
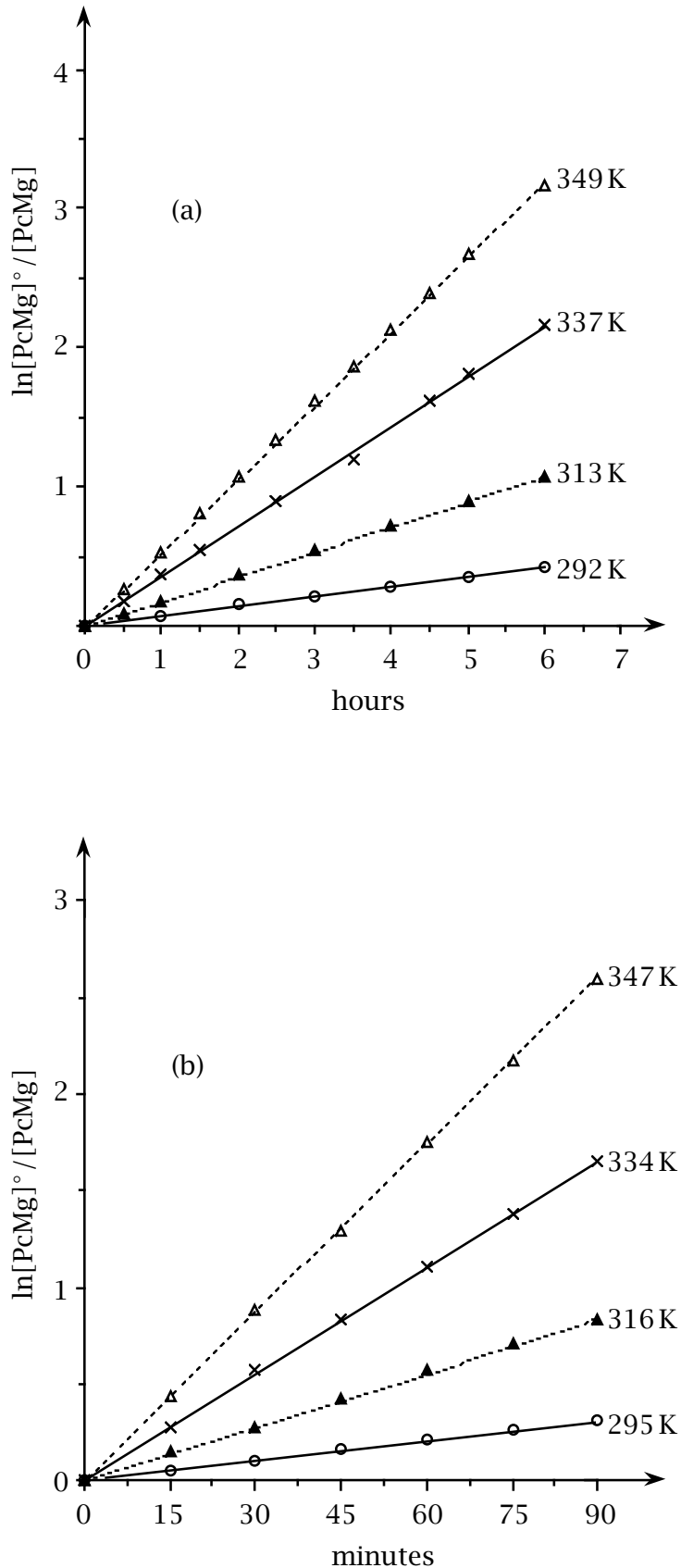

Figure 4. Variation with time of $\ln \left([\mathrm{MgPc}]^{\circ} /[\mathrm{MgPc}]\right)$ at different temperatures in the presence of: (a) 1,4-dihydroxyanthraquinone; (b) 1,2,4-trihydroxyanthraquinone.

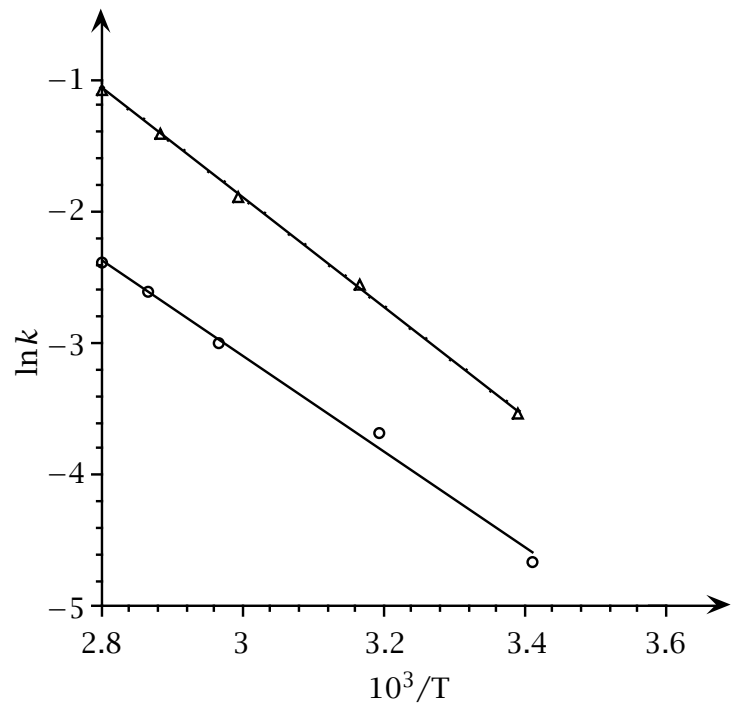

Figure 5. Change of the logarithm of the MgPc demetalation rate constant versus the reciprocal of the temperature in the presence of (-) 1,4-dihydroxyanthraquinone and (- - ) 1,2,4-trihydroxyanthraquinone in DMF solution.

the metal and the tetrapyrrole ligand. Thus, lithium, sodium, and magnesium which have smaller atomic diameters than the ligand cavity give electrovalent bonds with the ligand while the other metals form stable covalent bonds [38, 39].

\section{EXPERIMENTAL SECTION}

5.1. Compounds and solvents. The phthalocyanines (Eastman Kodak) are purified by sublimation between 340 and $400^{\circ} \mathrm{C}$ under high vacuum $\left(10^{-6}\right.$ Torr $)$. Those (MgPc, ZnPc) soluble in ethanol have been recrystallized twice in this solvent. $\mathrm{H}_{2} \mathrm{Pc}$ and TiPc have been filtered after being refluxed successively for several hours in ethanol and dichloromethane. The others have been purified in a Soxlet under reflux of chloroform during eight hours.

The anthraquinones have been purified by thin layer chromatography using 85:15 benzene/ethyl acetate or 1:1 (v:v) benzene/diethylether mixtures as eluent. Their purity has been checked by HPLC using a Varian model 219 apparatus.

Dimethylformamide (Merck) has been purified by vacuum distillation $(0.1 \mathrm{mmHg})$ followed with chro- 
matography over alumina which had been dried several hours at $100^{\circ} \mathrm{C}$. Dichloromethane (Merck), chloroform (Merck) and ethanol (Prolabo), all three of spectroscopic quality, have been used as received.

Each phthalocyanine solution was filtrated through a $5 \mu \mathrm{m}$ Millipore system in order to eliminate the particules which would have not been dissolved.

5.2. Fluorescence. The fluorescence spectra of the phthalocyanines have been obtained with a Perkin-Elmer MPF 44B spectrofluorimeter equipped with a DCSU2 spectral correction unit. The optical density of the solutions at the long-wavelength excitation $(640 \mathrm{~nm})$ is kept $\leq 0.05$ in order to limit the partial reabsorption of the emitted light. The excitation spectra of all the phthalocyanines coincide with their absorption spectra.

The fluorescence quantum yields were determined by comparison with the known value of 0.54 for Cresyl Violet [27].

The lifetime of the phthalocyanines lowest singlet excited state has been obtained by direct measurement of the fluorescence decay after excitation with a $30 \mathrm{ps}$ fwhm pulse at $355 \mathrm{~nm}$ of a frequency-tripled YAG laser described in a previous article [40], and recorded with a Tektronix model 7912 AD digitized oscilloscope.

5.3. Demetalation. The demetalation reactions are carried out in a quartz cuvette in a degased dimethylformamide solution containing $\operatorname{MgPc}\left(10^{-5} \mathrm{M}\right)$ with an excess $\left(10^{-3} \mathrm{M}\right)$ of 1,4-dihydroxyanthraquinone or 1,2,4-trihydroxyanthraquinone. The cuvette is put in a copper holder with a water circulation thermostated at $\pm 0.1{ }^{\circ} \mathrm{C}$. The cuvette and its holder are put in a Varian-Cary 219 spectrophotometer and the absorption spectra are recorded every hour (for 1,4dihydroxyanthraquinone) and every 15 minutes for 1,2,4-trihydroxyanthraquinone.

\section{REFERENCES}

[1] H. Eckut and A. Schier, Angew. Chem. Intern. Ed. in English 2 (1981), 280.

[2] M. G. Lagorio, L. E. Dicelio, and E. A. San Roman, J. Photochem. Photobiol. A 3 (1989), 615.

[3] T. Shen, Z.-L. Yuan, and H.-J. Xu, Dyes and Pigments 11 (1989), 77.

[4] P. S. Vincett, E. M. Voigt, and K. E. Rieckhoff, J. Chem. Phys. 55 (1971), 4131.

[5] D. Chahraoui and J. Kossanyi, J. Chim. Phys. 89 (1992), 47.

[6] A. T. Gradyushko, A. N. Sevchenko, K. N. Solovyov, and M. P. Tsvirko, Photochem. Photobiol. 11 (1970), 387.

[7] P. G. Seybold and M. Gouterman, J. Mol. Spectrosc. 31 (1969), 1.

[8] S. Y. Shen, L. Li, Q. F. Zhou, H.-J. Xu, and H. Z. Wang, Chinese Chem. Letters 1 (1990), 201.

[9] J. F. Muller, J. M. Magar, D. Cagniant, J. Grimblot, and J. P. Bonnelle, J. Organometal. Chem. 186 (1980), 389.
[10] J. F. Muller, J. M. Magar, D. Cagniant, J. M. Mouchot, J. Grimblot, and J. P. Bonnelle, J. Organometal. Chem. 205 (1981), 329.

[11] B. G. Silbernagel, J. Catalysis 56 (1979), 315.

[12] P. C. H. Mitchell and J. A. Valero, Inorg. Chim. Acta 71 (1983), 179.

[13] G. R. Berezina, N. A. Kolesnikov, and R. P. Smirnov, Khim. Geterotsikl. Soedin (1990), 268.

[14] C. W. Hung and J. Wei, Ind. Eng. Chem. Process Res. Dev. 19 (1980), 257.

[15] J. H. Espenson and R. J. Christensen, Inorg. Chem. 16 (1977), 2561.

[16] K. A. Martin and M. J. Stillman, Inorg. Chem. 19 (1980), 2473.

[17] Th. Foerster, Organic Charge Transfer Complexe, Org. Ser. Monogr. 15 (1969).

[18] V. Wintgens, J. Pouliquen, and J. Kossanyi, Nouv. J. Chim. 9 (1985), 229.

[19] V. Wintgens, M. Pouliquen, J. Simalty, J. Kossanyi, F. K. Justensen, and J. Eriksen, J. Photochem. 26 (1984), 131.

[20] T. Nyokong, Z. Gasyna, and M. J. Stillman, Inorg. Chem. 26 (1987), 548.

[21] H. Ohtani, T. Kobayashi, T. Tanno, A. Yamada, D. Woehrle, and T. Ohno, Photochem. Photobiol. 44 (1986), 125.

[22] H. Ohtani, T. Kobayashi, T. Ohno, S. Kato, T. Tanno, and A. Yamada, J. Phys. Chem. 88 (1984), 4431.

[23] J. R. Darwent, P. Douglas, A. Harriman, G. Porter, and M.-C. Richoux, Coord. Chem. Rev. 44 (1982), 83.

[24] J. R. Darwent, I. McCubbin, and D. Phillips, J. Chem. Soc. Faraday Trans. II 78 (1982), 347.

[25] A. Harriman, G. Porter, and M.-C. Richoux, J. Chem. Soc. Faraday Trans. II 77 (1981), 1175.

[26] T. Tanno, D. Woehrle, M. Kaneko, and A. Yamada, Ber. Bunsenges. Phys. Chem. 84 (1980), 1032.

[27] D. Magde, J. H. Brannon, T. L. Cremers, and J. Olmsted III, J. Phys. Chem. 83 (1979), 696.

[28] J. McVie, R. S. Sinclair, and T. G. Truscott, J. Chem. Soc. Faraday Trans. II 74 (1970), 1870.

[29] I. Kawenoki, B. Keita, J. Kossanyi, and L. Nadjo, Nouv. J. Chim. 6 (1982), 6, 387.

[30] D. Chahraoui, Ph.D. thesis, Paris (France), June 1991.

[31] Y. Nishimura, Y. Kaneko, T. Arai, H. Sakuragi, K. Tokumaru, M. Kiten, S. Yamamura, and D. Matsugana, Chem. Lett. (1990), 1935.

[32] D. Rehm and A. Weller, Isr. J. Chem. 8 (1970), 259.

[33] , Ber. Bunsenges. Phys. Chem. 73 (1969), 834.

[34] H. Leonhardt and A. Weller, Ber. Bunsenges. Phys. Chem. 67 (1963), 791.

[35] A. Kumar and P. Neta, J. Phys. Chem. 85 (1981), 2830.

[36] A. Giraudeau, A. Louati, H. J. Callot, and M. Gross, Inorg. Chem. 20 (1981), 769.

[37] M. El Meray, A. Louati, J. Simon, A. Giraudeau, M. Gross, T. Malinski, and K. M. Kadish, Inorg. Chem. 23 (1984), 2606. 
[38] F. H. Moser and A. L. Thomas, Phthalocyanine Compounds, 80 Amer. Chem. Soc. Monograph Series, vol. 157, Reinhold Publ. Comp., NY, 1963.

[39] A. B. P. Lever, H. J. Emeleus, and A. G. Sharpe ed., in
“The Phthalocyanines", 28, vol. 7, Academic, 1965.

[40] P. Valat, V. Wintgens, J. Kossanyi, L. Biczòk, A. Demeter, and T. Bérces, J. Amer. Chem. Soc. 114 (1992), 946. 


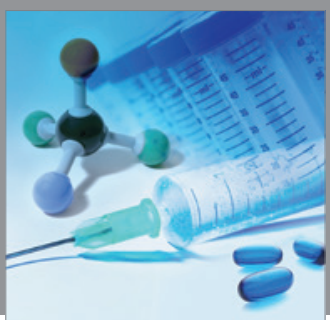

International Journal of

Medicinal Chemistry

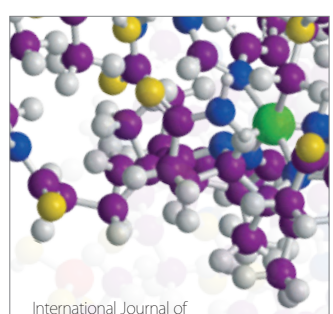

Carbohydrate Chemistry

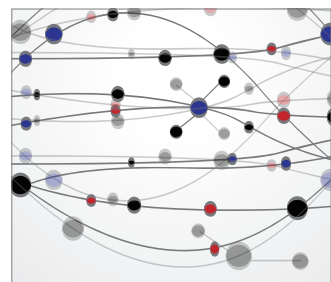

The Scientific World Journal
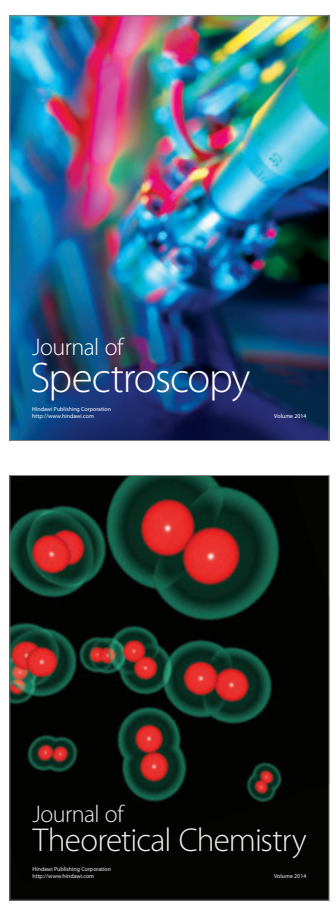
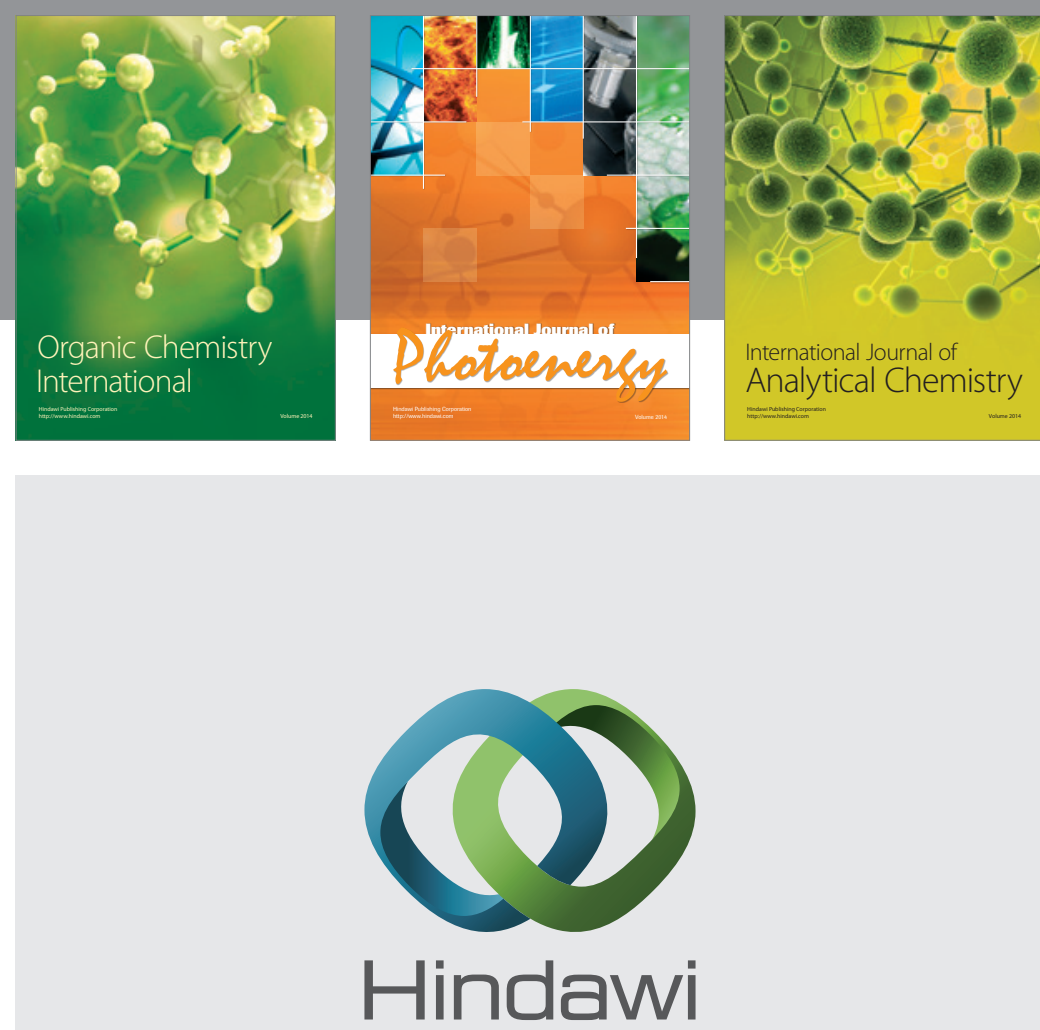

Submit your manuscripts at

http://www.hindawi.com
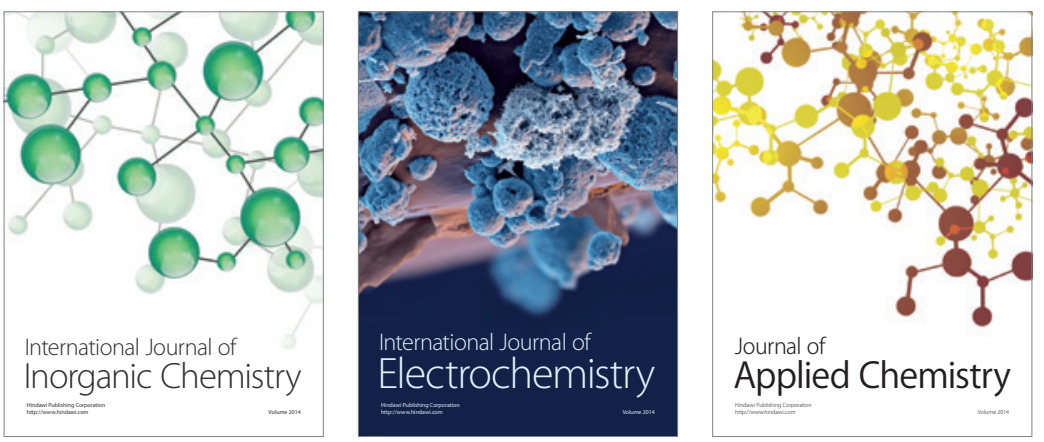

Journal of

Applied Chemistry
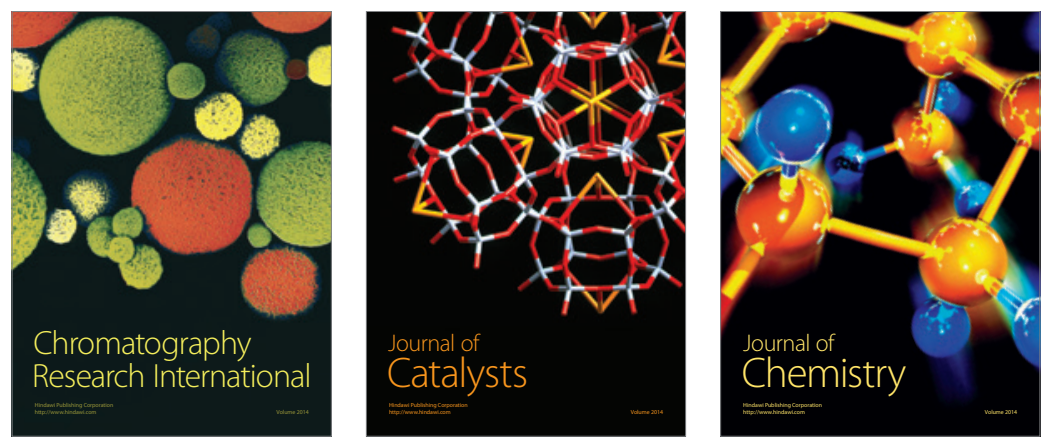
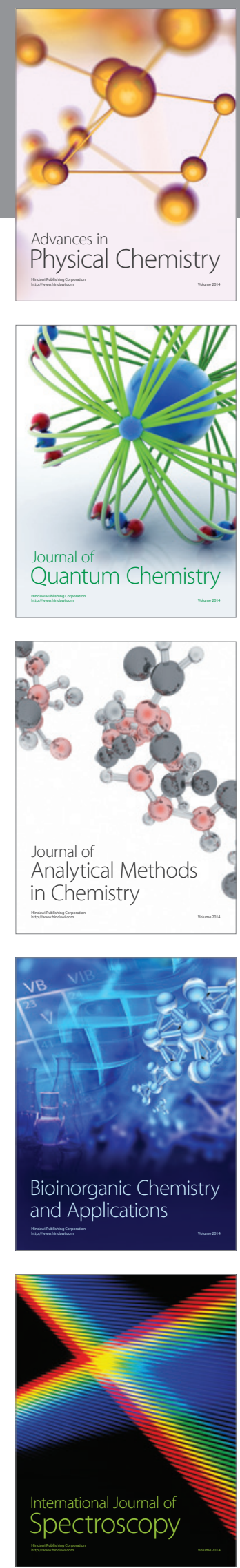